\title{
Porque Usía es condesa
}

\author{
Florentina y Benicia Vidal Galache
}

\begin{abstract}
RESUMEN
En el año 1840 los liberales destituyeron a la Real Junta de Damas de Honor y Mérito en la dirección de la Inclusa y del Colegio de Nuestra Señora de la Paz, donde se acogía a los expósitos de Madrid. Los liberales pensaban que el Estado se debia encargar de la ayuda a los necesitados y que la beneficencia no podía depender de la caridad privada, como venía sucediendo desde siglos atrás. Pero el intento de institucionalizar la beneficencia no obtuvo el éxito esperado y en 1848 los liberales repusieron a la Real Junta de

Damas en la dirección de ambos orfelinatos.

PALABRAS CLAVE Inclusa. Colegio de Nuestra Señora de la Paz. Expósitos. Real Junta de Damas de Honor y Mérito. Beneficencia. Liberales. ABSTRACT

In 1840, the liberals dismissed the Real Junta de Damas de Honor y Mérito [Royal Board of Honor and Merit Ladies] from the management of the Inclusa [foundling hospital] and of the School of Our Lady of the Peace, where the foundlings of Madrid were given refuge.

The liberals thought that the State should take charge of the assistance to those in need, and that the beneficence should not depend on the private charity, as it had happened during the previous centuries. But the attemp of instifutionalizing the beneficence did not succeed as expected, so in 1848 the liberals reinstated the Royal Board of Ladies in the direction of the two orphanages. Inclusa. The School of Our Lady of the Peace. Foundlings. The Roal Board of Honor and Merit Ladies. Beneficence. The Liberals.
\end{abstract}


«Porque Usía es condesa

que va en litera, que va en litera...»

Tan grande era el número de sus pajes y lacayos que, de haberlo querido, la condesa-duquesa de Benavente no se habría molestado en subir ni un solo peldaño de la majestuosa escalera de su palacio, próximo a las Vistillas. De hecho subía con mucha frecuencia otras escaleras infinitamente más modestas, las de un enorme y tétrico caseron de la calle de Embajadores, en el corazón de uno de los denominados «barrios bajos" de Madrid, habitado mayoritariamente por personas de humilde extracción.

María Josefa Alonso Pimentel reunía en su persona, entre otros, los títulos de duquesa de Bejar, de Gandía, de Arcos, de Monteagudo, princesa de Esquilache y de Anglona, condesa de Mayorga, de Boñares de Benalcázar, de Osilo y de Coguinas, marquesa de Manchini, de Lombay y de Jabalquinto; era cuatro veces grade de España, condesa-duquesa de Benavente por derecho propio y duquesa de Osuna desde que en 1771 se casó con su primo, Pedro de Alcántara, noveno duque de ese título y militar de profesión que en 1794, cuando era teniente general, luchó bravamente contra Francia en una de las repetidas contiendas que arruinaron de forma catastrófica a la Hacienda española.

¿Qué hacía una mujer de tan alta alcurnia, que además era dueña de una inmensa fortuna, frecuentando un barrio reputado por su vecindario de alborotador y bullanguero? La condesa-duquesa no buscaba emociones entre majas y chisperos, como su rival la de Alba; su destino era una institución nacida en el Barroco bajo los imperativos de la caridad cristiana, dedicada a la recogida de expósitos: el Hospital de Nuestra Señora de la Caridad y San José, más conocido entre el pueblo de Madrid como la Inclusa. En el mismo inmueble, pero con fachada a la calle de Embajadores, estaba el Colegio de Nuestra Señora de la Paz, creado dos siglos atrás por otra aristócrata para acoger y educar a las niñas expuestas a partir de los siete años. Ambos orfanatos habían sido puestos por el rey bajo la dirección de la Real Junta de Damas de Honor y Mérito, presidida en varias ocasiones por la condesa-duquesa ${ }^{\dagger}$.

El 9 de octubre de 1840 la Real Junta de Damas Nobles fue cesada en la dirección de la Inclusa y Colegio de la Paz por el Ayuntamiento liberal;

Sobre la Inclusa y Colegio de Nuestra Señora de la Paz en el siglo xIx véase de Vidal Galache, F. y B.:Bordes y Bastardos. Una historia de la Inclusa de Madrid. Madrid. E.Compañia Literaria, 1995. También: De princesas, señoras y otras clases de mujeres, (Nerea-UNED), en prensa. 
atrás quedaban más de cuarenta años de esfuerzo y entusiasmo en favor de los niños expósitos madrileños.

De forma dramática se cerró una etapa en la vida de los dos orfanatos, ajenos a la lucha desencadenda entre el régimen absolutista, caduco y agonizante y el de los liberales exaltados, que tenían por primera vez a un militar en el poder, e iban a hacer de la independencia municipal la clave de su vida política?

\section{ESTABLECIMIENTOS MADRILEÑOS DE ASISTENCIA A LOS EXPÓSITOS}

La Inclusa de Madrid fue fundada en 1567 por la Cofradía de Nuestra Señora de la Soledad y las Angustias, para recoger y criar niños abandonados. El problema de los expósitos resurgía con toda su crudeza cuando terminaban su crianza, a los siete años. No eran muchos los que llegaban a esa edad y la suerte que esperaba a los supervientes era incierta y cruel; algunos eran reclamados por sus padres o adoptados, generalmente por las mismas amas que los habían amamantado, pero la mayoría volvian a la Inclusa donde se les buscaba empleo como aprendices y sirvientes. Habia un importante contingente de criaturas que desaparecía sin dejar rastro: unos eran utilizados por picaros que los adiestraban para pedir limosna o cometer pequeños hurtos y los más vagaban por las calles hasta morir de hambre y de frío. En 1674 se fundó el Hospicio de Madrid y desde ese momento también fueron enviados allí niños procedentes de la inclusa, entre ellos los disminuidos físicos (tullidos, ciegos), para aprender un oficio y convivír con miserables de todas las edades y condiciones.

La Congregación del Amor de Dios fundó en el año 1596 el Hospital y Albergue de Pobres Desamaparados, dedicándolo a varias actividades caritativas con poca relación entre sí: asistencia a paridas pobres, albergue nocturno de menesterosos sin techo, amparo de ancianas impedidas y recogida de niñas y niños abandonados a los que procuraba una formación profesional y a los expósitos que quedaban en una total indefensión al terminar su crianza en la Inclusa ${ }^{3}$. Una manda testamentaria de D. a Ana Fernández de Córdoba, duquesa de Feria, daría origen en el año 1679 a un establecimiento similar para las niñas expuestas de Madrid, el Colegio de Nuestra Señora de la Paz.

Martin Muñoz, J.: La política local en el Madrid de Pontejos. Madrid. Caja de Madrid, 1995. Véase de SIMON PALMER, M. C.: El Colegio de los niños Desamparados de Madrid. Anales del Instituto de Estudios Madrileños (A.I.E.M.), XV, (1978) 63-84 y VIDAL GALACHE, F. y B. op. cit. en n 1 
Las tres instituciones (Inclusa, Colegio de los Desamparados y Colegio de la Paz) fueron planteadas según los principios de la moral cristiana, que basaba la salvación del alma en el ajercicio de la caridad, haciendo de la ayuda a los más necesitados una obligación de todo buen creyente. Las cofradías fundadoras de la Inclusa y Colegio de los Desamparados estaban integradas por personas pertenecientes a todos los estratos sociales, unidos por vínculos más espirituales que legales, que se encargaban personalmente de su dirección y financiación, basada fundamentalmente en limosnas y rentas de bienes procedentes de legados y mandas testamentarias. Con el tiempo, la importancia de su labor social las hizo pasar a patronazgo de la Corona; asi consiguieron rentas fijas, basadas generalmente en impuestos sobre productos de consumo, y se beneficiaron en momentos de necesidad de la paternalista caridad real. El rey puso su dirección en manos del Consejo de Castilla, que ya no tuvo contacto directo con sus complejos problemas al delegar en altos dignatarios, denominados jueces protectores, que se limitaban a una fría labor de gestión.

A principios del siglo $x \mid x$, casi todos los centros benéficos de patronato regio fueron relevados por Carlos IV de la tutela del Consejo de Castilla, para ser dirigidos por juntas de nobles de corte ilustrado. En 1799, la Real Junta de Damas de Honor y Mérito, dependiente de la Sociedad Económica Matritense, fue encargada de la dirección de la Inclusa y siete años después de la del Colegio de la Paz. Las Damas, que merecieron la confianza regia por su labor al frente de las Escuelas $\mathrm{Pa}$ trióticas, intentaron también hacerse con el control del Colegio de los Desamparados, pero el rey lo puso en manos de la Junta Colegiada de Nobles de Madrid.

\section{LA INCLUSA BAJO LA DIRECCIÓN DE LA JUNTA DE DAMAS}

La Junta de Damas de Honor y Mérito, creada en 1787, estuvo desde sus comienzos promovida e integrada por mujeres de la nobleza y capas altas de la sociedad, que junto a una gran inquietud intelectual y humana tenían el deseo de ser consideradas como elementos útiles; planteamiento insólito entre las féminas de alta cuna, que no se destacaban por sus preocupaciones sobre el mundo del trabajo.

Aparentemente los requisitos para formar parte de la Junta de Damas eran muy simples: buena educación, buena conducta y conocimiento e interés por los problemas que se iban a afrontar; de hecho limitaban las po- 
sibilidades a un reducido grupo de mujeres cultivadas, pertenecientes en su mayoría a las clases privilegiadas ${ }^{4}$.

Las emprendedoras mujeres tuvieron que mantener una dura lucha para ser admitidas como socias de la Real Sociedad Económica Matriten$\mathrm{se}^{5}$, venciendo las reticencias de muchos de sus miembros ilustres que no las creían capaces de realizar actividades de interés. En aquella actitud generalizada de irónico recelo hubo algunas excepciones, como la del ministro Campomanes que consideraba la admisión de mujeres «no sólo justa sino conveniente y necesaria" ${ }^{6}$, y que siguiendo en la línea iniciada por Manuel José Marín ${ }^{7}$ apoyó decididamente la inclusión de las mujeres como miembros de pleno derecho.

Por el contrario, Cabarrús se opuso de manera rotunda al proyecto por considerar a las señoras un elemento discordante y peligroso para la Sociedad, siempre dispuestas a alterar con su actitud poco reflexiva las graves meditaciones y tareas que en ella se gestaban. A su entender, solo eran posibles candidatas las mujeres que por su edad hubieran perdido "las gracias de su sexo" ${ }^{8}$, momento en el que cabía la posibilidad de que llegaran a adquirir alguna de las virtudes que adornaban naturalmente a los hombres.

Transcurrieron doce años, desde 1775 en que D. José Marín presentó en Real Sociedad una memoria sobre la necesidad de la admisión de mujeres, hasta la promulgación de la Real Orden de 27 de agosto de 1787 , que permitió la creación de la Junta de Damas, adscrita a la Matritense. En España fue ésta la primera asociación de mujeres autorizada por el rey, exceptuando las asociaciones religiosas como monasterios, cofradías, etc., que tenían un carácter esencialmente piadoso ${ }^{9}$.

En 1789, la condesa de Trullas, presidenta de la Junta pidió permiso al rey para realizar una inspección en la Inclusa, pero no se le permitió. Unos

4 Sobre este punto véase de Rios IzQuiendo, P. y Rueda Roncal, A.: «Análisis de las normas jurídicas de la Junta de Damas de Honor y Mérito". Torre de los Lujanes, 13, 1989, pp. 151-161.

5 Véase Demerson, Paula: Maria Francisca de Sales y Portocarrero (Condesa de Montijo). Una figura de la llustración. Madrid, Taurus, 1975, pp. 127-143 y NEGRIN, Olegario: Ilustración y Educación: la Sociedad Económica Matritense, Madrid, E. Nacional, 1984.

6 Rodriguez Campomanes, P.: Memoria presentada a la Sociedad de Madrid por su individuo el señor conde de Campomanes en 18 de noviembre de 1775 sobre la admisión de señoras en ella. Archivo Real Sociedad Económica Matritense (A.R.S.E.M.). Leg. 3-27.

Memoria leída en la junta de 28 de octubre de 1775. A.R.S.M. Lgs. 3-36 y 5-10.

8 Memoria leída el 18 de febrero de 1786. A.R.S.E.M., leg, 73-44, recogida por NEGRiN, O., en su opus cit. en $n^{\circ} 5$, pp. 150-156.

Sempere y Guarinos, J.: Ensayo de una biblioteca española de los mejores escritores del reinado de Carlos III. Madrid, 1789, t. V. p. 213. 
años más tarde fue públicamente reconocida por el soberano como muy meritoria la labor realizada por las Damas en las cuatro Escuelas Patrióticas -San Sebastián, San Ginés, San Martín y San Andrés-y en las escuelas femeninas de bordados, blondas y otras labores, dependientes de la Sociedad Económica Matritense. Animada por los elogios reales, la condesa de Montijo, secretaria de la Junta, solicitó nuevamente permiso para inspeccionar la Inclusa, y el 16 de enero de 1796 obtuvo al fín la recompensa a su tenacidad.

Cuando la comisión formada por la condesa de Montijo, la condesa de Trullas, la duquesa de Arija y doña Francisca Raón inició su investigación ${ }^{10}$ encontró que, como resultado de la pésima gestión llevada durante muchos años, las rentas de la Institución eran escasas, la atención a los niños en extremo deficiente y la mortalidad muy alta. Una Real Orden de 13 de septiembre de 1799 concedió a las señoras la dirección de la Inclusa.

\section{REFORMAS DOMÉSTICAS}

La Junta de Damas intentó una mejora en la calidad de vida de la Inclusa aún a costa de que los gastos aumentaran de forma considerable ${ }^{11}$. En febrero de 1800 contrataron un segundo médico celador, un oficial de libros y organizaron una enfermería, donde se podría aislar a los niños y evitar la propagación de enfermedades infecciosas, como la sarna, muy extendida entre los bebés. El mismo año se incorporaron al servicio de la institución las Hermanas de la Caridad, que desempeñaron un papel fundamental en su buen orden y funcionamiento. La contratación de amas se realizó a partir de entonces en términos que suponían unas mejores condiciones para los expósitos.

Las Señoras reorganizaron la confusa economía de la Inclusa, actualizando algunas de sus rentas muchos tiempo descuidadas; procuraron nuevos ingresos desplegando su imaginación y su influencia en la organización de rifas (tuvieron gran aceptación las de cerdos, celebradas en primavera y otoño), subastas de joyas y objetos diversos procedentes de le-

10 Trullas, condesa (de): Memoria expositiva del estado de negocios de la Junta de Señoras. Madrid, 1796. A.R.S.C.M., fondos Inclusa. leg., 803, pq. 1. Sobre los comienzos de la actuación de la Junta de Damas en la Inclusa véase de DEMERSON, Paula: opus cit en n 5 y La Real Inclusa de Madrid a finales del siglo xvil, A.I.E.M. VIII, 1972, pp. 261-272.

11 Los datos sobre la organización, personal y gastos generales proceden del «Libro del gasto ordinario y extraordinario de la Real casa Inclusa (1792-1807)" Archivo Regional de la Comunidad de Madrid (A.R.C.M.) Fondos Inclusa, leg. 2041. 
gados, bailes de sociedad o corridas de toros, y llevando un control riguroso en los gastos.

A partir de 1820 las Damas se ocuparon de visitar periódicamente a los niños que se criaban con nodrizas externas en los barrios pobres de Madrid, retirando a los que se encontraban en peores condiciones. Todos los dias se enfrentaban con escenas de miseria y volvían a la Inclusa cargadas con bebés deshidratados, raquíticos, sifilíticos, tuberculosos o cubiertos de horribles lesiones cutáneas infectadas; algunos a punto de morir y otros ya cadáveres.

Muchas de las señoras costearon la crianza y educación de algunos de los pequeños, como la condesa-duquesa de Benavente, que tenía en su propia casa a dos incluseros, una niña llamada María Josefa y un chiquillo negro; la marquesa de Zilleruelo se encargó del niño Antonio Rafael y la misma duquesa de Alba, que no pertenecía a la Junta de Damas, prohijó a otra negrita llamada María de la Luz.

Para terminar con el gran peligro que suponía el traslado de los recién nacidos abandonados en pueblos o ciudades próximos hasta Madrid, las Damas decidieron que fueran criados en sus lugares de origen, bajo el control de los párrocos y las señoras notables de la localidad. Esta medida ahorró muchas vidas inocentes; los niños abandonados, en su mayoría recién nacidos, ya no tendrian que recorrer largas distancias hasta la Inclusa, conducidos por desaprensivos que los amontonaban en cuévanos o alforjas, a lomos de caballerías, y los dejaban sin comer ni beber durante horas, revueltos en sus propios excrementos y lágrimas.

\section{REFORMAS LEGALES}

Dentro de su política de integración en el mundo del trabajo de todos los sectores de la población no productiva, como mendigos, gitanos y otros marginados, los ilustrados habían promulgado una serie de reformas legales en favor de los expósitos que permitieran su plena incorporación en la sociedad. Entre las disposiciones destacan la Real Cédula de 23 de enero de 1794 por la que quedaron legitimados los expósitos de ambos sexos, existentes y futuros, que hizo posible su acceso a los oficios civiles que por su condición les habían estado negados, a la par que se prohibía, entre otras cosas, que fueran insultados con epítetos injuriosos como «bordes, bastardos, espúrios, incestuosos o adulterinos".

Otra Real Cédula de 11 de diciembre de 1796 daba un paso más para la inserción de estos niños en la todavía rígida sociedad estamental, dán- 
doles un reconocimiento social que hasta el momento no habían tenido, a la par que se daban normas sobre el funcionamiento de las Casas de Expósitos y la creación de otras nuevas, con el propósito de atajar los aterradores índices de mortalidad que se daban entre las criaturas expuestas.

En 1801 la condesa de Montijo, secretaria de la Junta de Damas, obtuvo un nuevo logro legal a favor de los incluseros al conseguir la derogación del artículo 25 del reglamento de Policía general de Expósitos, incluído en la Real Cédula de 1796, según el cual los padres perdían la patria potestad $y$ todos sus derechos sobre los hijos por el hecho de abandonarlos. El rey suprimió el artículo de forma transitoria, confiando la responsabilidad de la devolución de los niños a sus padres a la presidenta de la Junta.

\section{LOS CAMBIOS DE DOMICILIO DE LA INCLUSA Y COLEGIO DE LA PAZ}

A principios del siglo $x \mid x$ el edificio que albergaba a la Inclusa era el mismo adquirido dos siglos atrás por la Cofradía fundadora, en la calle de Preciados. Casi inmediatamente de asumir la dirección de la Inclusa, las Señoras empezaron a buscar otro alojamiento más adecuado, decidiéndose por una vivienda situada en la calle del Soldado, compuesta por una casa principal y otra casita pequeña que permitía la entrada a un jardín. En la calle Preciados quedó abierto un «depósito» con torno para los niños expuestos de forma anónima.

La Inclusa residió muy poco tiempo en la calle del Soldado y apenas un año después de la mudanza, en la correspondencia intercambiada por la condesa de Trullas y la duquesa de Osuna ${ }^{12}$ se mencionaba varias veces la conveniencia de instalar a los expósitos en el Colegio de las Niñas de la Paz ${ }^{13}$ cerrado en 1803. Las niñas de la Paz habían sido trasladadas al Colegio de los Desamparados y un año después a una pequeña casa de la calle del Prado, número 3. Las malas condiciones de la vivienda hicieron que la Junta de Damas, decidiera reabrir el Colegio de la calle Mesón de Paredes; el destierro, seguido de la muerte, de la condesa de Trullas retrasaron la medida hasta el 30 de septiembre de 1807. Ese mismo año la Inclusa fue trasladada a la calle de Embajadores a un edificio a espaldas del Colegio, y ambas instituciones fueron comunicados por una puerta interior.

12 Cf.: Oficios y cartas entre la condesa de Trullas y duquesa de Osuna (1803). A.R.C.M., fondos Inclusa, leg. 803

13 Cf.: Vidal Galache, B. y F.: Opus cit en n? 1 (1991). 
Las Damas instalaron su despacho en una oscura habitación, una sala cuadrada que servía de paso a otra mayor, decorada con una imagen de la Virgen, un Santo Cristo, 14 cuadros de reyes y santos en sus marcos dorados y 3 Niños-Dios estropeados, encerrados en fanalitos de cristal. Aquel cuarto destartalado era el escenario donde la presidenta de la Junta redactaba la memoria anual que resumía el precario estado de los dos orfanatos puestos bajo su cuidado. Un escrito donde se exponían las reformas realizadas y los planes de mejora, casi siempre abortados por falta de dinero y la triste realidad de las estadísticas que evienciaban el altísimo porcentaje de expósitos fallecidos. La mortalidad en la Inclusa, pese a las nuevas medidas higiénicas adoptadas y a los cambios de domicilio, continuó siendo el más grave problema.

A partir de 1811, pese a la ayuda concedida por José Bonaparte, la economía empezó ya a ser deficitaria, porque no se cobraban la mayor parte de las consignaciones cedidas por Fernando VII ${ }^{14}$. Con la vuelta al trono del Deseado las damas consiguieron nuevas asignaciones sobre rentas eclesiásticas y medicamentos gratuítos, servidos desde la Botica Real. La memoria presentada en 1816 por la condesa-duquesa de Benavente evidencia su alegría por la restauración de la monarquía absolutista en la persona de "nuestro legítimo, amado y suspirado Rey D. Fernando". Los soberanos hacian frecuentes visitas a las dos casas de expósitos, a veces sin previo aviso, que eran un medio de propaganda muy eficaz. En suma las Damas nunca consiguieron todo el dinero que necesitaban los niños abandonados, pero se sentían respaldadas por los monarcas a los que podían acudir con la familiaridad que les otorgaba su alto rango.

\section{EL TRIENIO LIBERAL}

En 1820 la llegada de los liberales al poder dio lugar al paso definitivo de la beneficencia a manos de la Administración. A lo largo de todo el Antiguo Régimen, la asistencia a los necesitados estuvo casi en su totalidad a cargo de la Iglesia y los particulares y fue Carlos III quien dio el primer paso hacia la institucionalización de la caridad, con un amplio Plan de Beneficencia que sería respetado por los últimos monarcas absolutistas.

\footnotetext{
14 Fuente HiJar, marquesa de y Fuente Nueva, condesa de: “Oficio a D. Joaquín Garcia Domenech", A.R.C.M., fondos Inclusa, leg. 762-4. En el mismo legajo hay un borrador, dirigido a D. Pablo Arribas, donde las Señoras amenazan con dejar la Inclusa si no reciben ayuda inmediata.
} 
Durante el trienio $1820-23$, los liberales intentaron la reforma total de la asistencia a todo el colectivo de necesitados por medio de una Ley General, promulgada en 1822, que sería el origen de toda la legislación dictada sobre esta controvertida cuestión a lo largo del siglo xix; los pobres quedarían a cargo de la Administración, siendo definido por vez primera el concepto de beneficencia pública como un servicio más del Gobierno a los ciudadanos de menos recursos ${ }^{15}$.

El problema más espinoso estaba en la forma de financiación y se pretendía que el Estado aportara la menor cantidad posible de dinero; para ello era necesaria la reorganización de la hospitalidad, haciendo desaparecer los centros privados que consideraban poco rentables y creando un fondo común formado con los bienes de todos los centros asistenciales, obras pias, memorias, etc., que sería administrado por el propio Estado. Dado el escaso tiempo de mandato liberal, la ley tuvo poca repercusión en esta primera fase.

El tono general del texto de la Memoria de la Junta de Damas del año 1820 permite adivinar que en aquellos primeros momentos del nuevo régimen liberal las señoras de la Junta de Damas confiaban que su trabajo iba a ser financiado por la Administración, como ya sucedía en otros países. Al no depender de unas rentas raquíticas, ni de la siempre voluble caridad privada, ni del paternalismo del rey, terminarían sus apuros económicos. Las señoras insistian sobre éstas peticiones con ardor habitual: «Todos las naciones mantienen estos asilos de caridad y beneficencia, y todos los gobiernos civilizados trabajan para sostenerlos y elevarlos al grado de perfección que reclaman imperiosamente la religión y la humanidad, en favor de los desgraciados".

Los liberales, que concebían la Beneficencia como un servicio del Estado al ciudadano, cuestionaron la forma de ejercer al caridad de las damas de la aristocracia, mermando sus competencias en unas materias ahora encomendadas a las autoridades civiles. Su condición de mujeres y de nobles pasó de ser un privilegio a ser un obstáculo. No obstante la Real Junta de Damas de Honor y Mérito fue la única asociación de su clase respetada en la dirección de establecimientos benéficos; se reconocía la eficacia de su gestión y su influencia entre los poderosos, a la hora de recaudar las limosnas que contribuía en buena parte a sostener los dos orfanatos.

Cuando 1823 se produce la vuelta a la monarquía absoluta las Damas continuaron su labor, contando siempre con las simpatías del monarca

15 Vidal Galache, F. y B.: ¿Caridad o justicia social? “A distancia», U.N.E.D., 1997. 
que le devuelve plenos poderes, y con la admiración del pueblo, no acostumbrado a ver a mujeres de tan alto rango dedicadas al cuidado de los más pobres entre los pobres.

\section{EL CESE FORZOSO DE LA JUNTA DE DAMAS: LA BATALLA POR LA INCLUSA}

En 1836, con el definitivo asentamiento de los liberales, fue puesta de nuevo en vigor la Ley General de Beneficencia de 1822 y restaurada la Junta Municipal de Beneficencia; en contra de lo establecido, la Junta de Damas vuelve a ser la única junta gubernativa de los establecimientos de beneficencia de Madrid que conservó su puesto, pero las atribuciones del Ayuntamiento progresista iban a ser muy importantes y se haran notar en el control sobre la vida de la capital.

En 1839 una aparente cuestión de competencias hizo que se rompiera la armonía entre la Junta de Damas y el municipio. Al morir el rector de la Inclusa y Colegio de la Paz, las Damas pretendieron cubrir la vacante con un candidato de su confianza, el antiguo vicerrector Cándido Antonio Heras $^{16}$.

El visitador de la Inclusa informó a la Junta Municipal de Beneficencia que la persona propuesta era adecuada, pero no era correcto el procedimiento seguido por las Damas para cubrir la vacante. Según el artículo 12 de la Ley de Beneficencia de 1822 entonces vigente, el nombramiento de jefes locales de las casas de beneficencia corría a cargo del Ayuntamiento, que elegía entre una terna de candidatos. El visitador propuso a tres individuos y pese a que figuraba en primer lugar el candidato de las Damas, fue elegido el segundo, el presbítero Mariano José Fontana.

El 23 de diciembre la Junta Municipal de Beneficencia comunicó a las señoras el fallo del concurso, advirtiéndoles que la Ley no les permitía tomar iniciativas sobre nombramientos y ceses del personal de la Inclusa.

En marzo de 1840 el nuevo rector fue nombrado oficialmente y se informó a la Junta de Damas que el visitador de la Inclusa le daría publicamente posesión de cargo. La respuesta de la presidenta de la Junta de

16 Toda la documentación relativa al incidente ésta en: Expediente relativo al nombramiento de rector (1839-1840). A.R.C.M., Fondos Inclusa, leg. 748, paquete 1, c. 6. 
Damas fue rápida y contundente: no les parecía adecuado el nombramiento, se ratificaban en su opinión de que el candidato idóneo era el suyo y no pensaban aceptar un nuevo rector hasta que no les llegara la confirmación del Gobierno de S.M., a quien ya habían consultado sobre la legalidad del procedimiento. Al mismo tiempo anunciaron a los empleados de la Inclusa que no pensaban admitir al rector impuesto por el Ayuntamiento liberal.

A partir de estos momentos se desencadenó una abierta lucha de poder; la primera batalla fue ganada por la Junta de Damas con la protección de la reina que mandó que se dejara nulo y sin efecto el nombramiento del rector Fontana, aprobando el propuesto por las Damas.

El Ayuntamiento liberal, aprovechando el poder que le proporcionó la llegada de Espartero a la Regencia en septiembre de 1840, desenterró su viejo anhelo de controlar la Inclusa. La Junta Provisional de Gobierno de la Provincia mandó que inmediatamente fuese repuesto el rector Fontana y se despidiera al protegido por las señoras.

La Junta de Damas no tuvo más remedio que aceptar, pero el enfrentamiento continuó de forma más solapada. El día señalado por la Junta Municipal para que el rector se hiciera cargo de los fondos de la institución, de manos de una comisión de las propias señoras, éstas no comparecieron, alegando que debían comunicar el traspaso a la asamblea de su Junta; viéndose en la necesidad de pagar a las amas de los pueblos, el rector y el vocal visitador rompieron la cerradura del arca donde se guardaba el dinero. Las Damas denunciaron el hecho ante el juez de primera instancia y el vergonzoso suceso llegó hasta la Audiencia Territorial, que pidió informes al Ayuntamiento.

El 9 de octubre de 1840 la duquesa de Gor entregó a los representates del Ayuntamiento la documentación y efectos de la Inclusa y Colegio de la Paz; las señoras tuvieron que ceder su cargo de dirección a la Junta Municipal de Beneficencia, abandonando el trabajo en favor de los incluseros que durante 41 años habían desarrollado con tanto esfuerzo y entusiasmo. El escandalo llegó a oídos de la prensa que en general se manifestó a favor de las Damas. La Junta Municipal de Beneficencia protestó indignada, exigiendo a los redactores que publicaran su versión sobre lo sucedido, bajo amenaza de aplicarles la Ley de Imprenta vigente ${ }^{17}$.

17 Carta de la Junta Municipal de Beneficencia a los periódicos:»El Correo Nacional», "El Eco del Comercio» y “El Corresponsal» (1840) A.R.C.M., Fondos Inclusa, leg. 748, paquete 2, c. 6. 


\section{AGRAVIADAS Y OFENDIDAS}

Poco tiempo después, en febrero de 1841 , la Junta Municipal de Beneficencia llamaba a las Señoras -en un atento oficio- para que organizaran las cuestaciones de Semana Santa a favor de los expósitos, invitándolas a formar una comisión que colaborara en otros actos destinados a recaudar dinero para la Inclusa. Una vez comprobado que la ausencia de las Damas había hecho disminuir notablemente las limosnas, el Ayuntamiento no tuvo escrúpulos en solicitar su ayuda extraoficial.

La petición, seguramente esperada, debió causar satisfación y hasta regocijo entre las señoras porque la secretaria de la Junta, Margarita Elisa Norigat, se negó rotundamente a realizar la cuestación, y remitió al Ayuntamiento una copia del cese en la Inclusa de su corporación.

La lucha continuó algún tiempo. En 1844, en una nota al periódico Amigos del Pais, la Junta Municipal anunciaba que la Inclusa y el Colegio de la Paz abririan sus puertas a todas aquellas personas que desearan visitarlos. Así podrian comprobar que, gracias a sus desvelos, cada año se habían salvado $2 / 3$ de las criaturas, muchas más que en la etapa de las Damas. Entre las mejoras introducidas en la Inclusa podrian ver la nueva "sala de aseo", con capacidad para quince niños. Aprovechaban la ocasión para pedir a los visitantes una limosna que contribuyera a saldar la deuda pendiente con las nodrizas.

Pocos días más tarde se publicaron dos artículos en el mismo periódico que hacian grandes elogios de las extraordinarias reformas y mejoras realizadas en la Inclusa, atribuyéndolas a la Junta de Damas. Daba gran importancia a la solicitud maternal con que eran tratados los niños, actitud que ninguna asociación de hombres hubiera podido dispensar. Dado que la Junta de Damas había cesado en ese cargo cuatro años antes, los artículos, o bien son el indicio de que la prensa del momento estaba muy mal informada, o habian sido inspirados por las propias señoras para que la sociedad madrileña no olvidara el papel que habian representado durante años entre la infancia desvalida.

El 20 de abril de 1844 la Junta Municipal de Beneficencia, amenazando con la aplicación de la Ley de Imprenta vigente, exigió la inmediata rectificación por parte del periódico, recordando que las Señoras habían sido destituidas en 1840 y haciendo serias acusaciones sobre su gestión en la Inclusa. Decian también que al hacerse cargo la Junta Municipal de la Inclusa, las deudas pendientes ascendían a 121.510 reales, de nóminas de empleados, y 1.655 .878 de las nodrizas; la Inclusa había caído en el descrédito más notable y no se encontraban amas para los niños «...que mo- 
rian de forma horrible y en tal abundancia que en el último quinquenio que (las señoras) dirigieron el establecimiento de 6986 criaturas que tuvieron de entrada murieron 6386, resultando que solo se había salvado la vida a 600 ...". La Junta Municipal también se lamentaban del poco aprecio que la sociedad daba a sus esfuerzos al cuestionar que una asociación de hombres fuera capaz de una atención a los huérfanos tan esmerada como la ofrecida por las Damas.

Las acusaciones que se hacian a las Damas sobre la enorme mortalidad en la Inclusa en el último quinquenio de su mandato, se acercaban bastante a la realidad; incluso hubo dos años, 1837 y 1838, en que el número de niños muertos excedió al de ingresados. En 1837 hubo alteraciones en los abastos de pan que pasó a valer de 10 a 15 cuartos la hogaza, durante el asedio a la capital por las fuerzas carlistas. Las carencias afectaron al sector más débil de la población y hubo un aumento de ingresos y fallecimientos en la Inclusa, que era la caja de resonancia de la miseria de la capital.

Es importante destacar que la mortalidad de los niños que se criaban dentro de la Inclusa era muy superior, en cifras absolutas, a los muertos en casa de las amas externas. El porcentaje de muertos dentro de la Inclusa, entre $1800-1850$, fue del $80 \%$ por termino medio y fuera del $20 \%$. También es cierto que habia una marcada preferencia por dar a criar fuera a los niños que llegaban en mejores condiciones físicas, porque tenían más probabilidades de sobrevivir. Por esas razones, a partir de 1815 de forma paralela al incremento de ingresos se enviaron cada vez más niños a criar fuera, a la vez que la tasa de mortalidad fuera se mantuvo en cifras estables. Como consecuencia, las cifras de mortalidad absoluta empiezan a descender a partir de 1819 y la población infantil a cargo de la lnclusa muestra una tendencia al crecimiento, más acusado a partir de $1840{ }^{18}$.

La mortalidad infantil en general era altísima en esta época. La medicina ofrecía muy pocos remedios eficaces, con la excepción de la vacuna antivariólica que supuso un gran paso en la prevención de la enfermedad. Para la conservación del niño era fundamental una crianza adecuada, medidas higiénicas y, sobre todo, la alimentación, que era la base de la salud de las criaturas. En 1844, cuando la Junta Municipal se siente tan satisfecha de su gestión, el problema de la contratación de amas adecuadas seguía pendiente, porque la situación económica de la Inclusa era aún peor

18 Los porcentajes han sido elaborados tomando como fuente los "Resumenes anuales de criaturas... desde $1^{\circ}$ de enero de $1787 .$. " que abarcan el período 1787-1842. A.R.C.M. Leg. 825 . 
que en los primeros años del siglo; las rentas, como las de los demás establecimientos públicos, habían ido decreciendo con las distintas medidas económicas de los liberales y las limosnas también se habían reducido. A la vista de todo esto parece ridícula la polémica sobre la mortalidad de los expósitos, en el fondo una lucha de competencias. Unos y otros sabían la razón primordial del desastre: la falta de amas a consecuencia de la falta de dinero.

También es evidente en ocasiones la mala fe de la Junta Municipal al exponer de forma equívoca las deudas contraídas por las Señoras, y que no eran más que una forma de pago aplazado que ellos mismos siguieron utilizando. Por ejemplo, en 1840 la Junta Municipal decía que las Damas durante su mandato habían contraido una enorme deuda con las nodrizas, 1.655 .878 reales. En 1844, la Junta Municipal pedía la contribución de los ciudadanos para abonar a las nodrizas esa misma cantidad, porque cada seis meses se planteaba de forma inevitable el pago atrasado a las amas. Pese a la prepotencia demostrada en los primeros años, los responsables de la Junta Municipal no fueron capaces de recaudar los fondos necesarios para hacer frente a los pagos previstos.

Los problemas de la Inclusa no se resolvieron durante la gestión liberal. La Ley de Beneficencia de 1822 fue una hermosa teoría que no encontró el eco necesario en la sociedad que no veía con buenos ojos la suma de competencias asumida por los Ayuntamientos. El sentimiento religioso, muy enraizado aún en la mayor parte del pueblo, chocó frontalmente con la pretensión de los liberales de terminar con la caridad privada; los fondos de establecimientos de asistencia privados -en su mayoría pequeños hospitales para colectivos reducidos- no fueron intervenidos porque sus patronos, gentes de gran prestigio social, no permitieron la injerencia del Gobierno, y el planteamiento económico para la financiación de la Beneficencia se vió sin su principal fuente de ingresos. Por otra parte, se privó los centros benéficos del dinero que les proporcionaban los numerosos impuestos cedidos por la Corona y por la Iglesia, al tiempo que se les gravaba con nuevos tributos, como los que pesaron sobre sus inmuebles a patir de 1845 . El déficit de la Hacienda y los gastos generados por la guerra carlista, absorbieron parte del presupuesto destinado a beneficencia, que cada vez tenía más población que atender, y la calidad de vida en sus establecimientos había sufrido a mediados del siglo xIX un evidente deterioro.

En 1849, al pasar la Inclusa y Colegio de la Paz a ser responsabilidad de la Diputación, según lo ordenado en la nueva ley de Beneficencia promulgada dentro de la etapa moderada de la Administración liberal, las se- 
ñoras fueron repuestas en la dirección de ambos establecimientos. Es evidente la influencia de la Corona en las instituciones locales y en el control de la vida municipal (el alcalde-corregidor es de nuevo de elección real) y el Gobierno, asumiendo su incapacidad para resolver los problemas de la beneficencia, volvió a aceptar la colaboración de entidades particulares como la Junta de Damas,... aunque fueran mujeres y nobles. 